Original Research Paper

\title{
Efficiency of Hybrid MPPT Techniques Based on ANN and PSO for Photovoltaic Systems under Partially Shading Conditions
}

\author{
Max Tatsuhiko Mitsuya and Anderson Alvarenga de Moura Meneses \\ ${ }^{1}$ Postgraduate Program in Amazon Natural Resources, Laboratory of Computational Intelligence, \\ Federal University of Western Pará, Santarém, PA, Brazil
}

Article history

Received: 28-08 2019

Revised: 28-09-2019

Accepted: 30-09-2019

Corresponding Author:

Max T. Mitsuya,

Postgraduate Program in

Amazon Natural Resources,

Laboratory of Computational

Intelligence - Federal

University of Western Pará,

Santarém, Brazil

Email: maxmitsuya@eetepa.g12.br

\begin{abstract}
Hybrid Maximum Power Point Tracking (MPPT) algorithms have been investigated as an alternative to improve the performance of conventional MPPT, such as Perturb and Observe ( $\mathrm{P} \& \mathrm{O})$, Incremental Conductance (InC) and Hill Climbing (HC) in Photovoltaic (PV) systems under Partially Shading Condition (PSC). In the present article, Artificial Neural Network (ANN) and Particle Swarm Optimization (PSO) hybridized with $\mathrm{P} \& \mathrm{O}$ algorithm for MPPT are compared in terms of power efficiency. This paper not only compare hybrid MPPT methods against conventional MPPT, but also provide a comparison between two different hybrid techniques. In order to evaluate the performance of such hybrid methods, a PV system was computationally modelled and different PSC scenarios were implemented in MATLAB ${ }^{\circledR} /$ Simulink, as well as the hybrid methods $\mathrm{ANN}+\mathrm{P} \& \mathrm{O}$ and $\mathrm{PSO}+\mathrm{P} \& \mathrm{O}$. The hybrid methods $\mathrm{ANN}+\mathrm{P} \& \mathrm{O}$ and $\mathrm{PSO}+\mathrm{P} \& \mathrm{O}$ successfully improve the efficiency of $\mathrm{P} \& \mathrm{O}$ algorithm, respectively achieving $98.93 \%$ and $92.96 \%$ on average in the PSC scenarios tested, whereas $\mathrm{P} \& \mathrm{O}$ achieved $88.27 \%$ on average in such scenarios.
\end{abstract}

Keywords: Photovoltaic Systems, Hybrid Maximum Power Point Tracking, Artificial Neural Network, Particle Swarm Optimization, Perturb and Observe

\section{Introduction}

PV systems are a strategic renewable energy source for rural electrification and for supplying power to isolated communities (Gómez and Silveira, 2015) aiming very fundamental activities such as household lighting, water pumping, and preserving food and medicine in refrigerators. However, the performance of a PV system depends on climate variables, such as solar irradiance and ambient temperature (due to its influence in the cell temperature), and load profile (due to the load impedance).

In order to extract the maximum power of PV systems for any irradiance and temperature levels, it is desirable that PV systems operate in the Maximum Power Point (MPP). Thus, it is possible to insert a DC/DC converter with a computing system that will modify the duty cycle according to the search method and implicitly the input impedance of the converter until the system reaches the MPP, overcoming undesired effects on the output power. The process of searching this operation point is called Maximum Power Point Tracking (MPPT) (Karami et al., 2017) and the techniques used for reaching the MPP are called MPPT algorithms. According to variations in environmental conditions, the $\mathrm{P}-\mathrm{V}$ curve exhibits variations on the MPP, which is a challenge to MPPT algorithms. The situation becomes more complex in cases of Partially Shaded Conditions (PSC), when the module of PV array receives non-uniform solar irradiance. Then, the P-V curve exhibits multiple Local Maximum Power Point (LMPP) and one Global Maximum Power Point (GMPP). For such conditions, several global MPPT algorithms based on soft computing have been introduced (Ishaque et al., 2012b; Nabipour et al., 2017; Jiang et al., 2013a; Shaiek et al., 2013; Ahmed and Salam, 2014; Rezk et al., 2017), such as Artificial Neural Network (ANN) (Haykin, 1999) and optimization metaheuristics such as Particle Swarm Optimization - PSO (Kennedy and Eberhart, 1995).

Under PSC, many conventional algorithms, such as Hill Climbing (HC) (Ons and Aymen, 2016), Perturb and Observe (P\&O) (Femia et al., 2005; Ahmed and Salam, 2015), Incremental Conductance (InC) (Loukriz et al., 2016) and Fractional Open-Circuit Voltage (FVoc) (Xiao et al., 2007), might be trapped in a LMPP, mostly because the tracking characteristics of these algorithms cannot differentiate between the LMPP and GMPP. In order 
to overcome these disadvantages, several approaches have been applied, improving such algorithms and making them capable of reaching the MPP under PSC (e.g., Femia et al., 2005; Ahmed and Salam, 2015; Devi et al., 2017).

Another alternative is the hybridization of methods. Basically, hybridization consists in the combination of two different MPPT algorithms. Typically, an algorithm is used to search the region of GMPP identifying the corresponding value of voltage at the MPP. Then such value is used in a conventional MPPT, commonly $\mathrm{P} \& \mathrm{O}$ (Bataineh and Eid, 2018; Jiang et al., 2015; Jiang et al., 2013b; El-Helw et al., 2017), InC (Radjai et al., 2014; Punitha et al., 2013; Abdulkadir and Yatim, 2014) or HC (Chaieb and Sakly, 2018), in order to reach a GMPP. The primary advantage of those techniques is the capability of leading a conventional MPPT (such as $\mathrm{P} \& \mathrm{O}, \mathrm{InC}$ or $\mathrm{HC}$ ) to reach the GMPP under PSC and increase the efficiency of the system. Several works report the potential of hybrids methods under uniform and non-uniform conditions with simulation and experimental results. However, in such works the authors only compare the performance of hybrid methods to non-hybrid techniques, such as P\&O, InC, HC, PSO and DE. For example, Abdulkadir and Yatim (2014) and Manickam et al. (2016) compare their hybrid method to the conventional PSO method. In the same way, El-Helw et al. (2017), present results comparison between the proposed hybrid method and non-hybrid ANN technique.

Therefore in the present work a comparison between hybrid methods $\mathrm{ANN}+\mathrm{P} \& \mathrm{O}$ and $\mathrm{PSO}+\mathrm{P} \& \mathrm{O}$ is proposed by evaluating the PV power efficiency and energy difference of such methods under PSC. MATLAB/SIMULINK is used in order to simulate and evaluate the performance calculating the efficiency of each technique considering different Shading Patterns (SPs). The main contributions of the present work are: (i) a comparison between two different hybrid methods (ANN+P\&O and $\mathrm{PSO}+\mathrm{P} \& \mathrm{O}$ ) used to improve the $\mathrm{P} \& \mathrm{O}$ algorithm efficiency under PSC; and (ii) further analysis of the algorithms ANN, PSO and $\mathrm{P} \& \mathrm{O}$ for PV systems providing additional results for future studies and for the development of physical models.

\section{Related Work}

Batarseh and Zater (2018) reported 20 hybrid MPPT methods mentioned in literature that can be categorized into intelligent and non-intelligent techniques. Intelligent methods category includes techniques based on Fuzzy Logic Controllers (FLC) (Bataineh and Eid, 2018; Ajiatmo and Robandi, 2017), ANN (Jiang et al., 2015; Jiang et al., 2013b; El-Helw et al., 2017), PSO (Abdulkadir and Yatim, 2014; Manickam et al., 2016; Sundareswaran et al., 2015; Lian et al., 2014), and others such as Gravitational Search Algorithm (GSA) (Sundareswaran et al, 2016) and Simulated Annealing (SA) (Lyden and Haque, 2015). Most of such techniques perform the MPP search using two stages. Commonly, in the first stage the intelligent technique is used to recognize the region of GMPP and then in the second stage a conventional MPPT (e.g., P\&O, InC or HC) operates locally until the GMPP is reached.

\section{Hybrid MPPT Methods Based on ANN and PSO}

ANN and PSO are the two most employed techniques in combination with conventional MPPT algorithms under PSC. Therefore, the present section provides a specifically review of literature of the hybrid MPPT that combine ANN or PSO with conventional MPPT algorithms.

Jiang et al. $(2013 \mathrm{~b} ; 2015)$ proposed an ANN combined with $\mathrm{P} \& \mathrm{O}$ method. The authors used several SPs to simulate PSC and evaluated the proposed method in different scenarios. The simulations and experiments show that the technique enables P\&O to reach the MPP under PSC and is more efficient in comparison with other single techniques, such as conventional PSO. The major disadvantage is the requirement of large amount of data for ANN training process and the complexity for generation of this data in case of variations in irradiance and temperature (Nabipour et al., 2017).

El-Helw et al. (2017) proposed an improvement in the hybrid method ANN+P\&O implementing an ANN with two outputs, which represent the interval of voltage $\left(V_{\max }, V_{\min }\right)$ that includes the GMPP region, showing that such hybrid method can successfully achieve the GMPP more accurately.

Punitha et al. (2013) used an ANN to improve the conventional InC MPPT algorithm. When PSC occurs, the InC algorithm effectively finds the GMPP with reduced tracking time using an ANN as predictor of the value of reference voltage $\left(V_{r e f}\right)$.

Sundareswaran et al. (2015), combined a PSO algorithm with P\&O. The PSO is computationally simple and can be readily implemented on a low-cost digital controller. In some cases, the conventional PSO is trapped in an LMPP. Therefore, the authors proposed a hybrid method with PSO and P\&O algorithms. According to such approach the time for convergence of PSO is minimized. After the convergence of most particles, the P\&O method is initialized with its starting point as the position of the best particle in the PSO algorithm. In a similar way, Lian et al. (2014) present a hybrid method that use in the first stage a $\mathrm{P} \& \mathrm{O}$ algorithm for searching a LMPP.

Manickam et al. (2016) proposed another PSO and $\mathrm{P} \& \mathrm{O}$ hybridization, in which the $\mathrm{P} \& \mathrm{O}$ algorithm is only used to track the MPP under uniform conditions. When PSC occurs, the PSO algorithm is employed.

Abdulkadir and Yatim (2014) used a hybrid method with PSO and InC, using the same idea presented by Lian et al. (2014): The PSO method is initiated after the InC algorithm calculations converge to a value of voltage $\left(V_{\text {conv }}\right)$ in the first stage. 


\section{PV Array Modelling}

The PV module current (El-Helw et al., 2017) of a number of cells connected in series and/or parallel combinations each other is given by:

$$
I=I_{p v}-I_{0}\left[\exp \left(\frac{V+R_{S} I}{V_{t} a}\right)-1\right]-\frac{V+R_{S} I}{R_{p}}
$$

Where:

$V_{t}=\frac{N_{s} k T}{q}=$ Represents the thermal voltage with $N_{s}$ cells in series

$R_{s}$ and $R_{p}=$ The series and parallel resistances, respectively, and can be estimated iteratively (Villalva et al., 2009).

The photocurrent $I_{p v}$ is proportional to solar irradiance level and is also influenced by the temperature according to:

$$
I_{p v}=\left(I_{p v, n}+K i \Delta T\right) \frac{G}{G_{n}}
$$

Where:

$I_{p v, n}$

$=$ The nominal photocurrent at the nominal conditions, also known as Standard Test Conditions (STC), usually $25^{\circ} \mathrm{C}$ and $1000 \mathrm{~W} / \mathrm{m}^{2}$ (Villalva et al., 2009)

$K_{i}$

$=$ The short-circuit current/temperature coefficient

$\Delta_{T}=T-T_{n}$

$=\left(\mathrm{T}\right.$ and $T_{n}$ are the actual and nominal temperatures of the PV module)

$G\left(\mathrm{~W} / \mathrm{m}^{2}\right)$ and $G_{n}\left(\mathrm{~W} / \mathrm{m}^{2}\right)=$ The incident and nominal solar irradiance level

The diode saturation current is given by:

$I_{0}=I_{0 . n}\left(\frac{T_{n}}{T}\right)^{3} \exp \left[\frac{q E_{g}}{a k}\left(\frac{1}{T_{n}}-\frac{1}{T}\right)\right]$

where, $E_{g}$ is the bandgap energy, usually is considered $E_{g}=1.12 \mathrm{eV}$ for polycrystalline $\mathrm{Si}$ at $25^{\circ} \mathrm{C}$ (Villalva et al., 2009).

Still in Equation (2), $I_{0, n}$ is given by:

$$
I_{0, n}=\frac{I_{s c, n}}{\exp \left(V_{o c, n} / a v_{t, n}\right)-1}
$$

where, $I_{s c, n}$ and $V_{o c, n}$ represent the nominal short-circuit current and nominal open-circuit voltage. Generally such values can be found in PV modules datasheets.

The aforementioned equations are modelled with the parameters shown in Table 1 and simulated in MATLAB ${ }^{\circledR} /$ Simulink.

\section{The Effect of Partially Shaded Conditions}

In order to illustrate the PSC, consider a PV array composed by two strings, each having four sets of PV modules, as shown in Fig. 1a. String 1 consists of modules M1, M2, M3, and M4 connected in series. String 2 consists of modules M5, M6, M7 and M8, connected in series. According to Fig. 1a each module in the PV array is submitted to a different level of irradiance. In this situation, the voltage difference among the unequally insolated modules activates the bypass diode of the lower insolated string (Ishaque and Salam, 2013). Consequentially, the resulting P-V curve for each shaded string is characterized by a number of peaks equal to the number of unequally insolated modules, and the P-V curve of the PV array is the sum of the P-V curves of each string as shown in Fig. $1 \mathrm{~b}$.

Under uniform irradiance the MPP is usually located at around $80 \%$ of the open circuit voltage $V_{o c}$ (Radjai et al. 2014). Consequently, in PSC, the same condition occurs. Therefore, it is supposed that every LMPP in the PV curve is located sufficient closest of an integral multiple of $80 \%$ of $V_{o c}$ of a single PV module (Ishaque and Salam, 2013), so that:

$V_{\text {ref }}=C \times V_{o c} \times 0.8$

where, $C$ is an integer.

Particularly, if $C=1$, then Equation (5) is based on the same equation used in FVoc technique (Xiao et al., 2007).

\section{Hybrid Methods}

This section provides an overview of two soft computing techniques that are combined with conventional MPPT method in order to form a hybrid MPPT algorithm for improving the MPPT efficiency under PSC, namely the ANN+P\&O and the PSO+P\&O methods.

In order to explain these methods, let's consider the $\mathrm{P}-\mathrm{V}$ curve illustrated in Fig. 1b, in which there are four maxima (MPPs) respectively in four regions. The main idea of the hybrid MPPT methods is to identify the most promising region and then perform a local search. In the hybrid method $\mathrm{ANN}+\mathrm{P} \& \mathrm{O}$ the ANN estimates the region and then the conventional $\mathrm{P} \& \mathrm{O}$ locally searches for the GMPP. In the hybrid method PSO+P\&O, the stochastic algorithm PSO tries to reach the best duty cycle and then the P\&O algorithm locally searches for the GMPP. 
Max Tatsuhiko Mitsuya and Anderson Alvarenga de Moura Meneses / American Journal of Engineering and Applied Sciences 2019,12 (4): 460.471 DOI: 10.3844/ajeassp.2019.460.471

Table 1: PV module parameters

\begin{tabular}{ll}
\hline Parameters & Values \\
\hline Imp (Maximum Power Current) & $1.75(\mathrm{~A})$ \\
Vmp (Maximum Power Voltage) & $8.55(\mathrm{~V})$ \\
Pmp (Maximum Power Point) & $15(\mathrm{~W})(+10 \% /-5 \%)$ \\
Isc (Short-circuit Current) & $1.90(\mathrm{~A})$ \\
Voc (Open-circuit Voltage) & $10.55(\mathrm{~V})$ \\
Ki (Temp. coefficient of Isc) & $1.50 \times 10-3\left(\mathrm{~A} /{ }^{\circ} \mathrm{C}\right)$ \\
A (Ideal factor) & 1.3 \\
Rs (Series resistance) & $0.179(\Omega)$ \\
Rp (Parallel resistance) & $481.15(\Omega)$ \\
Ns (No of cell in series) & 18 \\
\hline
\end{tabular}

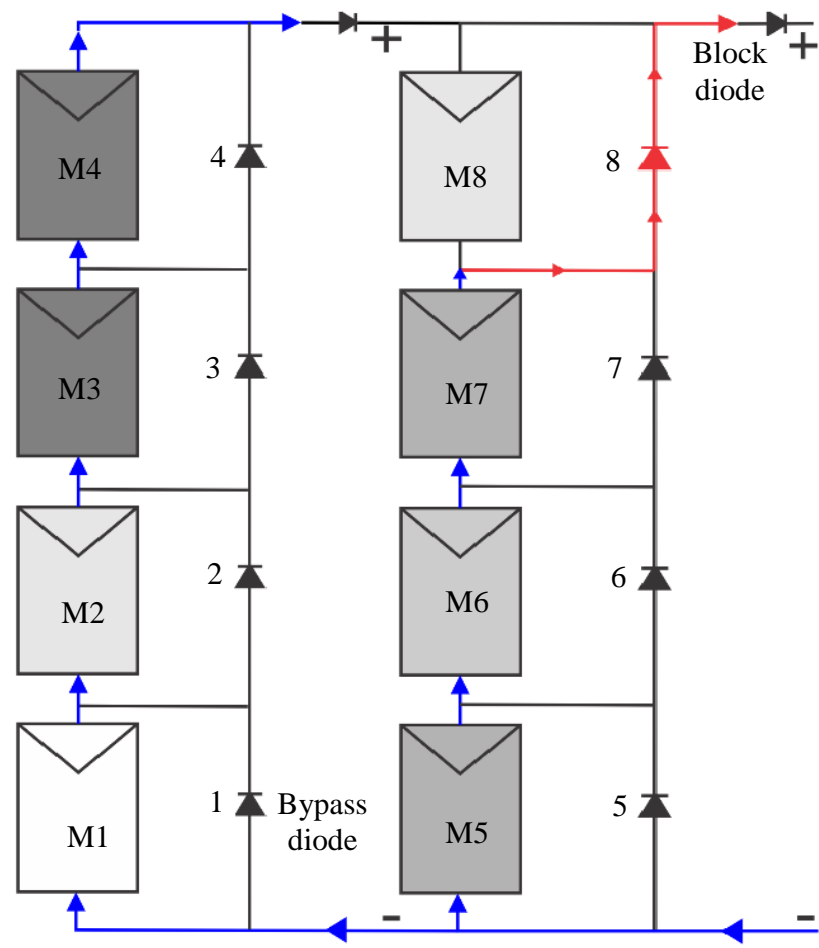

(a)

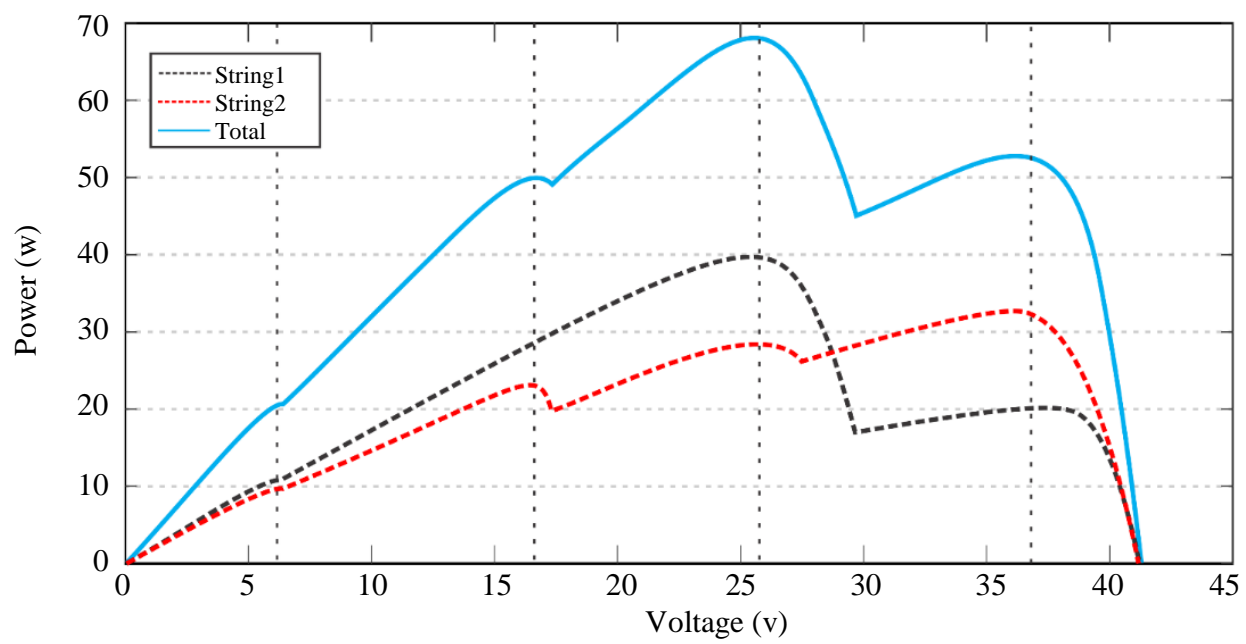

(b)

Fig. 1: (a) Configuration of the PV array under PSC. (b) P-V curve for each string and the resultant P-V curve of the entire array 


\section{Hybrid Method ANN+P\&O}

An ANN is a bioinspired distributed system with simple processing units, called neurons. During the training process, those neurons have the natural propensity for storing experiential knowledge and making it available (Haykin, 1999). ANNs execute tasks such as classification, regression, and pattern recognition. ANNs are applied in several fields of energy utilization, such as wind power systems, PV systems, and as controllers for hybrid energy systems. Regarding the MPPT problem, the ANN+P\&O method combines an ANN technique with conventional $\mathrm{P} \& \mathrm{O}$ method to track efficiently the MPP with fast tracking convergence, characteristic of the ANN method (Jiang et al., 2013b; 2015).

Firstly, the ANN train dataset is generated by a simulation of a PV array with four PV module in series, and each PV module is subject to irradiance and temperature levels. In order to simplify the model, the temperature is considered constant. The irradiance on each module varies from $100 \mathrm{~W} / \mathrm{m}^{2}$ to $1000 \mathrm{~W} / \mathrm{m}^{2}$, with a 50 $\mathrm{W} / \mathrm{m}^{2}$ step. Therefore, the ANN train dataset is composed by $19^{4}=130321$ input patterns, represented by the variations on irradiance of each module, and the same number of targets, which represent the region where the MPP is located. Furthermore, in order to improve the performance of the training process the output targets are coded in bits, as discussed by Jiang et al. (2013b).

As reported by Messalti et al. (2017) and Mitsuya and Meneses (2016), a Multilayer Perceptron (MLP) network presented the best performance as MPPT algorithm. Therefore, MLP was the architecture used in the present work. Table 2 shows the parameters of our MLP ANN implemented in MATLAB $®$ using the Neural Network Toolbox (Beale et al., 2015). The Levenberg-Marquardt (LM) training algorithm was chosen since it presents a good performance in nonlinear regression problems, such as MPPT problems.

After the training phase, the variables duty cycle $\left(D_{\text {ref }}\right)$, power output $\left(P_{\text {old }}\right)$ and the power change caused by a sudden irradiance change $\left(P_{\text {sudden }}\right)$ are initialized. $P_{\text {sudden }}$ represents a threshold indicating the occurrence of shading. When the difference between two subsequent power values is larger than $P_{\text {sudden }}$, then the ANN is used for predicting the region of the new MPP. Considering a constant load represented by a lead-acid battery, the $D_{\text {ref }}$ can be calculated by using Equation (5) and:

$$
D_{\text {ref }}=V_{\text {out }} / V_{\text {ref }}
$$

where, $D_{\text {ref }}$ is then used by the $\mathrm{P} \& \mathrm{O}$ algorithm for tracking the GMPP. In order to ensure the system stability at the new MPP, there is a time interval of $0.05 \mathrm{~s}$ before the MPPT is updated.
Table 2: ANN parameters

\begin{tabular}{ll}
\hline Parameters & Values \\
\hline $\begin{array}{l}\text { Lumber of Hidden } \\
\text { Numbers (HL) }\end{array}$ & 2 \\
$\begin{array}{l}\text { in each HL } \\
\text { Training Algorithm }\end{array}$ & 20 \\
\hline
\end{tabular}

\section{Hybrid Method PSO+P\&O}

PSO is a simple and efficient meta-heuristic inspired on the swarm behavior in groups of animals such as bird flocking and fish schooling (Kennedy and Eberhart, 1995). The application of PSO have yielded outstanding results in several areas in the field of power generation.

As mentioned by Miyatake et al. (2011), the PSO is a useful tool to determine the powerful energy management strategy so as cover all load demand at minimum operating cost while satisfying system equality and inequality constraints.

PSO can be applied to the optimization of multimodal functions (i.e., functions with multiple optima), which is particularly interesting for PV systems under PSC as Miyatake et al. (2011) proposed. In the $\mathrm{PSO}+\mathrm{P} \& \mathrm{O}$ method, a swarm of particles is used to search the best solution of the problem, and each particle represents a candidate solution. The position and velocity of a particle are computed according to:

$\vec{x}_{i}^{k+1}=\vec{x}_{i}^{k+1}+\vec{v}_{i}^{k+1}$

and:

$\vec{x}_{i}^{k+1}=\omega \vec{x}_{i}^{k}+c_{1} r_{1}^{k}\left\{\vec{p}_{b e s t, i}-\vec{x}_{i}^{k}\right\}+c_{2} r_{2}^{k}\left\{\vec{G}_{b e s t}-\vec{x}_{i}^{k}\right\}$

where, $k$ represents the $k^{\text {th }}$ iteration, $\omega$ is the inertia weight, $C_{1}$ and $C_{2}$ are the coefficients of acceleration, $r_{1}$ and $r_{2}$ are random numbers and $r_{1}, r_{2} \in U(0,1), \vec{P}_{b e s t, i}$ represents the best individual position of the particle $i$, and $\vec{G}_{b e s t}$ represents the best position of the entire swarm.

The PSO+P\&O hybrid algorithm in the present work is based on the method proposed by Sundareswaran et al. (2015). In Equation (7) and (8) the position vectors $\vec{x}_{i}$ (candidate solutions) contain values of the duty cycles.

\section{Simulations Settings}

According to Fig. 2, the model of PV system is composed by an array, with 4 modules connected in series and each module configured according to the Table 1 . The PV array is connected to a buck converter, with the following specifications: $C_{1}=2200 \mu \mathrm{F}, C_{2}=22$ $\mu \mathrm{F}$ and $L=453 \mu \mathrm{H}$. The frequency of the converter is set to $50 \mathrm{kHz}$, with a delay time $T_{d}=0,05 \mathrm{~s}$ to ensure the system stability before another MPPT cycle is initiated (Ishaque and Salam, 2013). A lead-acid battery with 12V of voltage represents the load. 
In order to ensure a fair assessment of the $\mathrm{PSO}+\mathrm{P} \& \mathrm{O}$ algorithm the simulation was executed ten times with different sequences of pseudorandom numbers, for each scenario tested. Table 3 shows the PSO parameters used in the tests.

Table 4 exhibits the set of SPs used for evaluating the performance of each of the three MPPT methods used in the present work. Such techniques are compared in terms of efficiency $\eta$ given by Jiang et al. (2015):

$\eta=\frac{\sum_{i=1}^{N_{a}} P_{i}}{\sum_{i=1}^{N_{a}} \operatorname{Prf} f_{i}} \times 100$

where, $P_{i}$ and $\operatorname{Prf}_{i}$ are the power obtained by applying the MPPT method and the theoretical maximum power at the $i^{\text {th }}$ sample time, respectively and $N_{a}$ represents the total sample time.

The energy difference between hybrid methods and $\mathrm{P} \& \mathrm{O}$ algorithm $\delta_{p}$ is given by Jiang et al. (2015):

$$
\delta_{p}=\frac{\sum_{i=1}^{N_{a}}\left|P_{H y b r i d}(i)-P_{P \& O}(i)\right|}{\sum_{i=1}^{N_{a}} P_{P \& O}(i)} \times 100
$$

where, $P_{H y b r i d}(i)$ and $P_{\rho \& o}(i)$ are the power obtained by hybrid and $\mathrm{P} \& \mathrm{O}$ method at the $i^{\text {th }}$ sample time, respectively, and $N_{a}$ represents the total sample time.

Different scenarios were tested in order to evaluate the performance and efficiency of the three algorithms. One scenario is the STC scenario (unshaded) and five scenarios are under PSC (PSC-1 to PSC-5) (Fig. 3). Under the STC, the PV arrays are submitted to an irradiance and temperature level equal to $1000 \mathrm{~W} / \mathrm{m}^{2}$ and $25^{\circ} \mathrm{C}$, respectively. In the first four scenarios under PSC, single transitions are used to represent a sudden irradiance change.

Therefore, in scenario PSC-1 a transition occurs from SP1 to SP2, sequentially we have for scenario PSC-2, $\mathrm{SP} 2$ to SP3, SP3 to SP4 in scenario PSC-3, and SP4 to $\mathrm{SP} 1$ in scenario PSC-4. The last scenario (PSC-5) constitutes multiple transitions of the SPs (SP5 to SP9), whose values are not included in the training data set of the ANN, for a more difficult search. The total simulation time is $5 \mathrm{~s}$ for scenario STC; 10 s for scenarios PSC-1, PSC-2, PSC-3, and PSC-4; and 25s for scenario PSC-5. Changes in SPs occur at each $5 \mathrm{~s}$ of the simulations, for the PSC scenarios.

Table 2: ANN Parameters

\begin{tabular}{lc}
\hline Parameters & Values \\
\hline Number of Hidden & 2 \\
Layers (HL) & 20 \\
Number of neurons & \\
in each HL & Levenberg-Marquardt \\
Training Algorithm
\end{tabular}

Table 3: PSO parameters

\begin{tabular}{lc}
\hline Parameters & Values \\
\hline Number of particles & 3.00 \\
$C_{1}$ & 1.00 \\
$C_{2}$ & 1.50 \\
$w$ & 0.27 \\
\hline
\end{tabular}

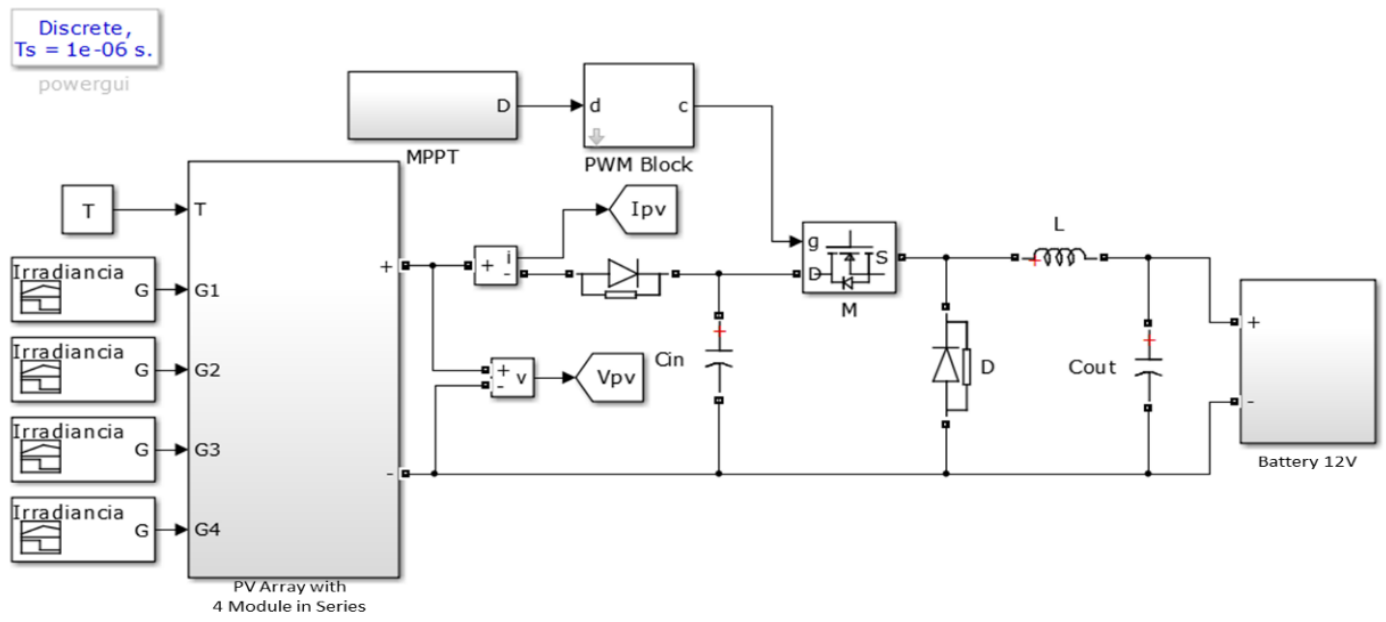

Fig. 2: Block diagram of the PV system 
Max Tatsuhiko Mitsuya and Anderson Alvarenga de Moura Meneses / American Journal of Engineering and Applied Sciences 2019 , 12 (4): 460.471 DOI: 10.3844/ajeassp.2019.460.471

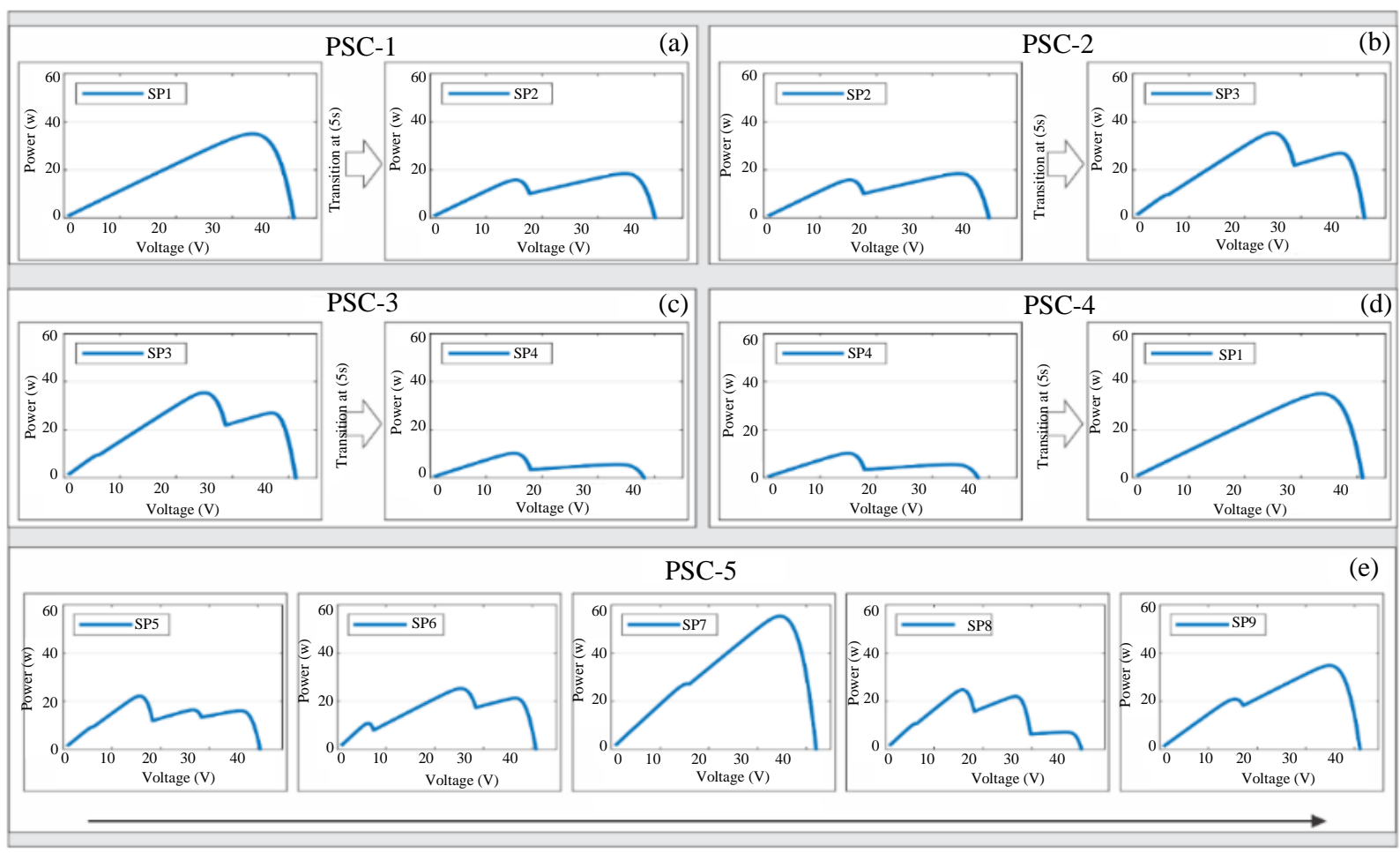

Fig. 3: P-V curves changes of all PSC Scenarios: (a) PSC-1; (b) PSC-2; (c) PSC-3; (d) PSC-4; (e) PSC-5

(a)
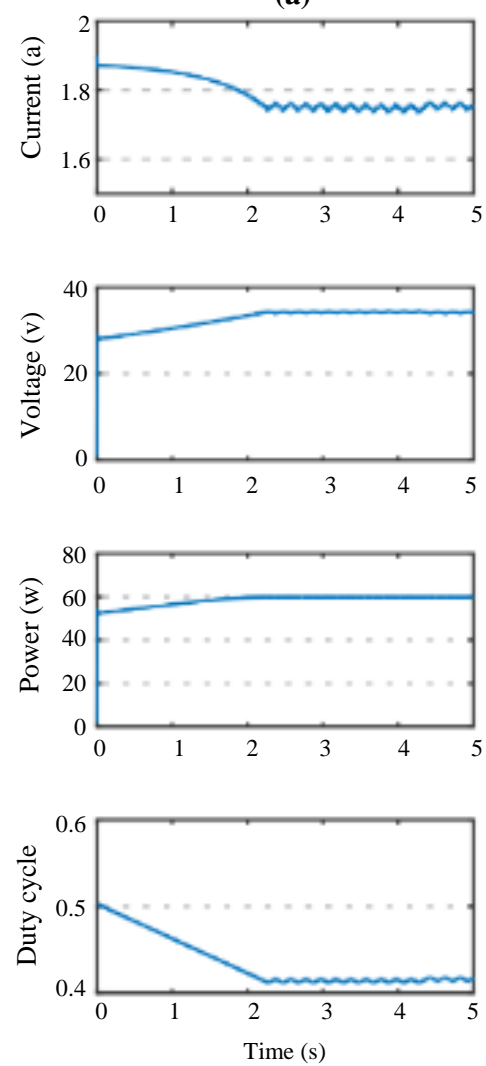

(b)
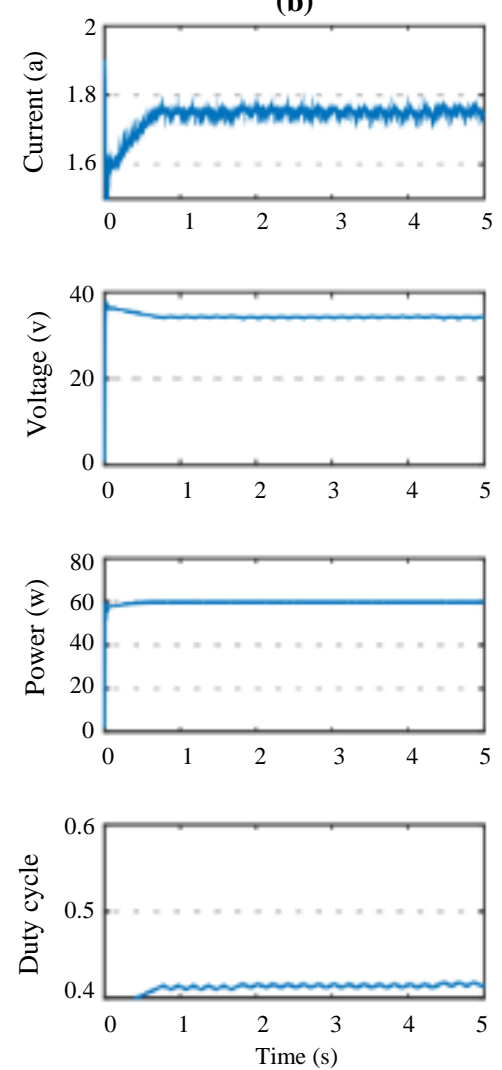

(c)
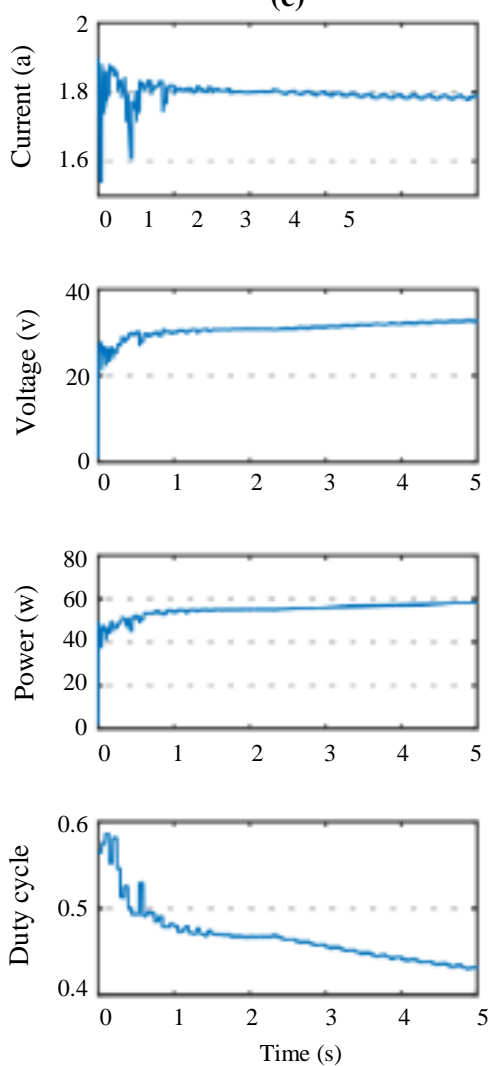

Fig. 4: Results for the STC scenario: (a) P\&O (b) Hybrid ANN+P\&O (c) Hybrid PSO+P\&O 


\section{Results and Discussions}

Figure 4 shows the performance of current, voltage, power, and duty cycle over time for the algorithms $\mathrm{P} \& \mathrm{O}$, $\mathrm{ANN}+\mathrm{P} \& \mathrm{O}$, and PSO+P\&O under STC. All algorithms reached the MPP (or nearly the MPP, in the case of $\mathrm{PSO}+\mathrm{P} \& \mathrm{O})$, however the tracking speed of ANN+P\&O is higher than the two other methods' speeds, taking less than 1s. Due to the uniform irradiance condition, which presents a single MPP, P\&O algorithm successfully reaches the MPP. PSO $+\mathrm{P} \& \mathrm{O}$ presented an oscillatory convergence, with maximum current, voltage and power respectively equal to $1.8 \mathrm{~A}, 30 \mathrm{~V}$ and $55 \mathrm{~W}$.

Figure 5 shows the results for $\mathrm{P} \& \mathrm{O}, \mathrm{ANN}+\mathrm{P} \& \mathrm{O}$, and $\mathrm{PSO}+\mathrm{P} \& \mathrm{O}$ under PSC. Regarding $\mathrm{P} \& \mathrm{O}$ in the scenario PSC-1, as shown in Fig. 5a, the algorithm reached the GMPP even when the transition of SPs occurs, at $5 \mathrm{~s}$. This occurs when GMPP is located at the same region in both SPs, Fig. 5a. However, for the scenarios PSC-2, PSC-3, and PSC-4, in Figs. 5b to5d, respectively, the $\mathrm{P} \& \mathrm{O}$ algorithm was trapped in LMPPs, hence extracting less energy than hybrid methods. The hybrid method ANN+P\&O successfully reached the GMPP in all scenarios tested, for in this method the ANN correctly determines the region with the GMPP and the $\mathrm{P} \& \mathrm{O}$ algorithm reaches the GMPP. Regarding $\mathrm{PSO}+\mathrm{P} \& \mathrm{O}$, the $\mathrm{PSO}$ algorithm took
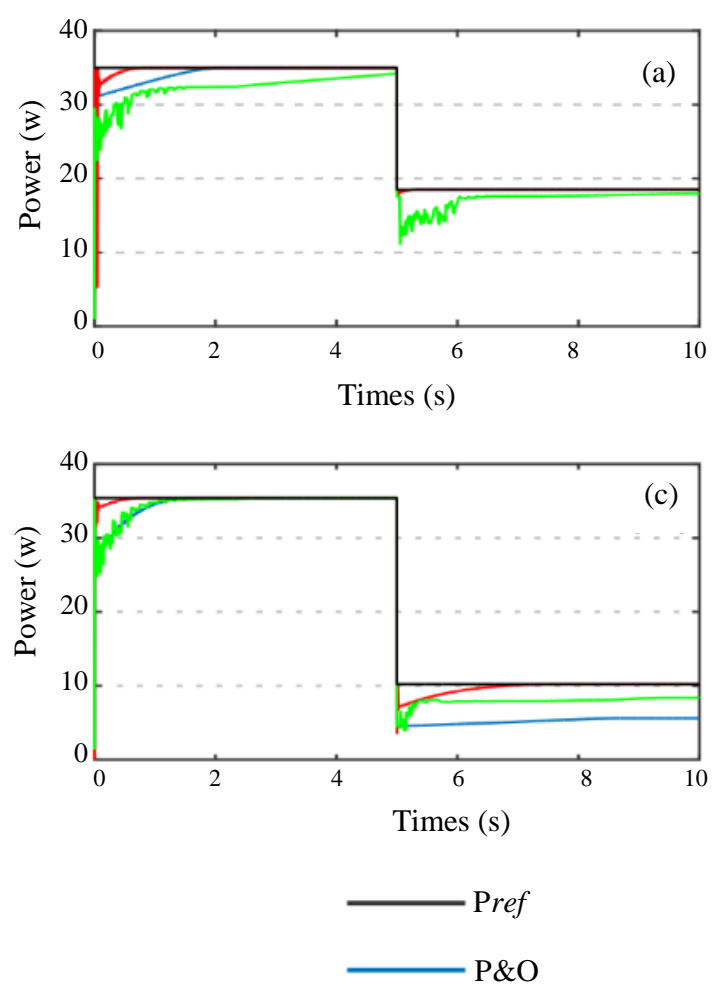

approximately $1.5 \mathrm{~s}$ to converge and then the best value found is used by the $\mathrm{P} \& \mathrm{O}$ algorithm to track the MPP. Considering Fig. 8b, when the SPs are changing the PSO algorithm successfully determines the best value for the $\mathrm{P} \& \mathrm{O}$ algorithm, but in other cases, such as scenarios 3 and 4 the PSO is trapped in an LMPP (Figs. $5 \mathrm{c}$ and $5 \mathrm{~d}$, respectively).

Figure 6 shows the results of $\mathrm{P} \& \mathrm{O}, \mathrm{ANN}+\mathrm{P} \& \mathrm{O}$, $\mathrm{PSO}+\mathrm{P} \& \mathrm{O}$ for the scenario 5. The hybrid method $A N N+P \& O$ successfully tracked the GMPP in all transitions. In cases which the GMPP is located in second region, for instance, in SP5 and SP8 (see Fig. 3(e)), ANN+P\&O takes more convergence time, mostly because $V_{\text {ref }}$ is approximately the voltage output (in this case the battery voltage).

Moreover, as reported by Jiang et al. (2015), the purpose of using the ANN combined with $\mathrm{P} \& \mathrm{O}$ is the classification of an approximate region of MPP, leading the $\mathrm{P} \& \mathrm{O}$ algorithm to reach the GMPP. The P\&O algorithm was trapped in LMPP extracting less power output of the PV system, as seen in the intervals $0-5 \mathrm{~s}$ and 15-20s. The PSO+P\&O algorithm was trapped in LMPP in some cases. However, as shown in Table 5, the effectiveness of this method changed according to the pseudorandom numbers generation.
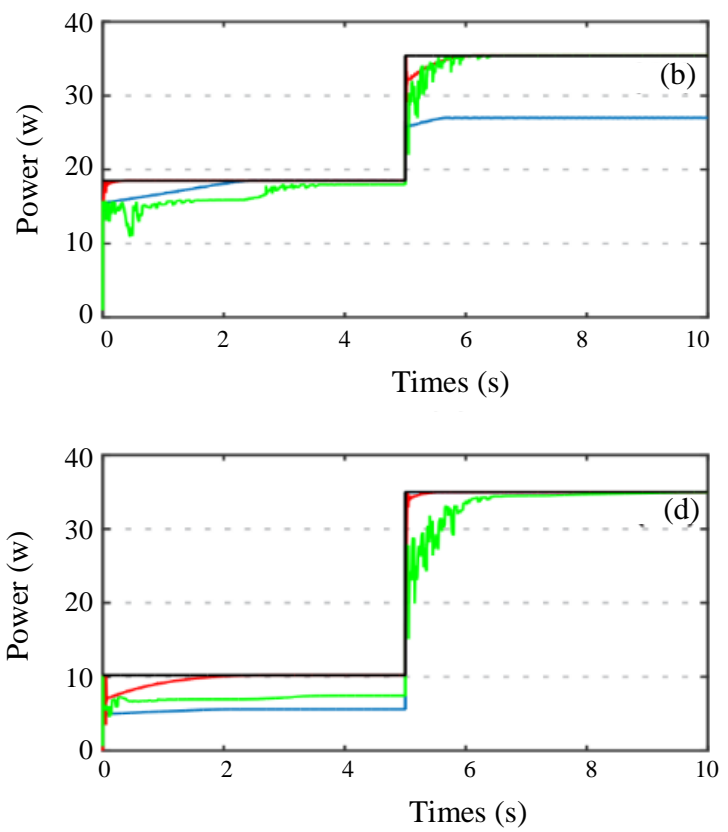

$\mathrm{ANN}+\mathrm{P} \& \mathrm{O}$

$\mathrm{PSO}+\mathrm{P} \& \mathrm{O}$

Fig. 5: Results for PSC with SPs changing from (a) SP1 to SP2 (scenario PSC-1); (b) SP2 to SP3 (scenario PSC-2); (c) SP3 to SP4 (scenario PSC-3) and (d) SP4 to SP1 (scenario PSC-4) 
Max Tatsuhiko Mitsuya and Anderson Alvarenga de Moura Meneses / American Journal of Engineering and Applied Sciences 2019,12 (4): 460.471 DOI: 10.3844/ajeassp.2019.460.471

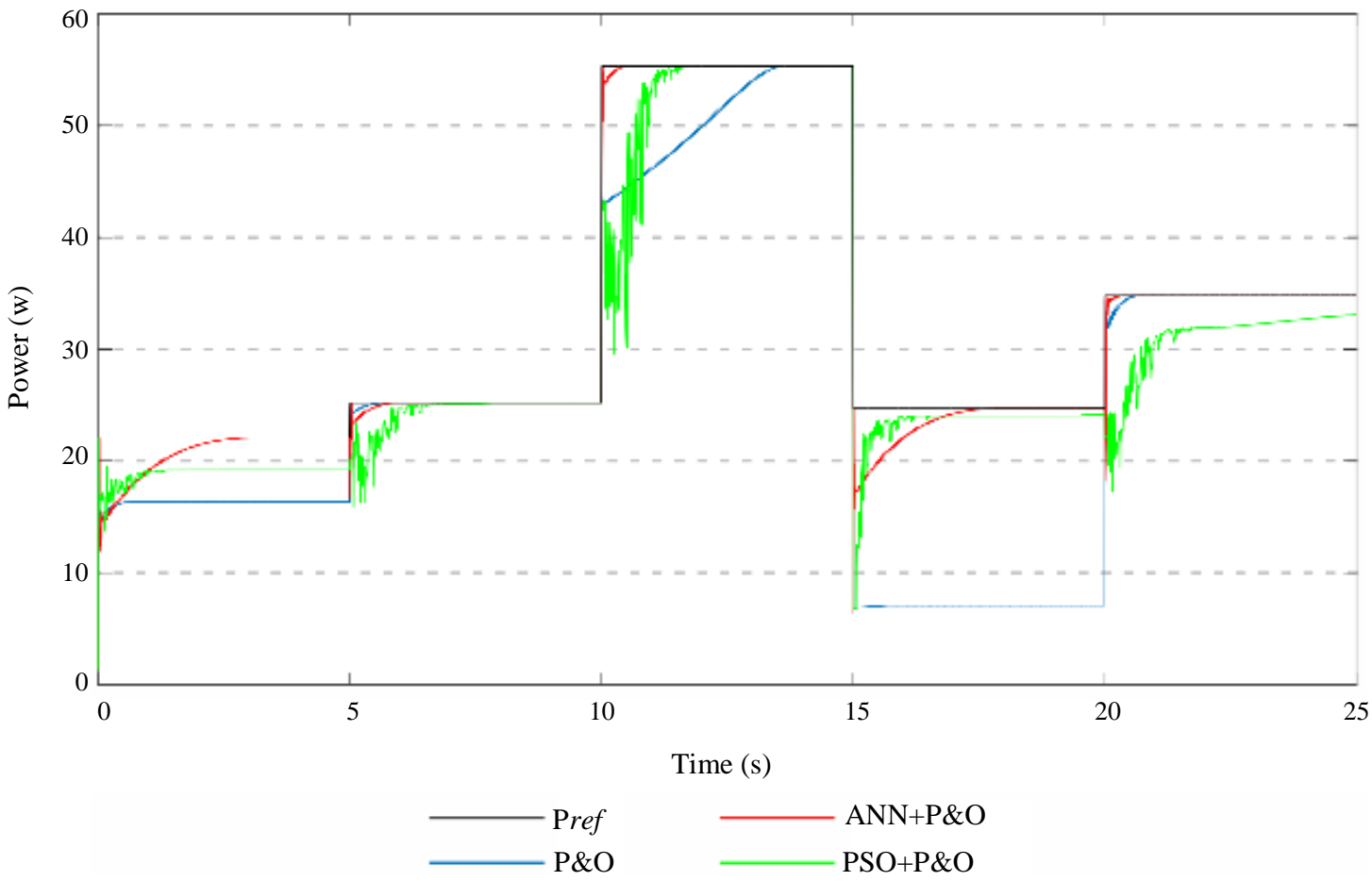

Fig. 6: Results of the methods $\mathrm{P} \& \mathrm{O}, \mathrm{ANN}+\mathrm{P} \& \mathrm{O}$, and $\mathrm{PSO}+\mathrm{P} \& \mathrm{O}$ for scenario PSC-5

Table 4: SPs used in the present work

\begin{tabular}{|c|c|c|c|c|c|c|}
\hline \multirow[t]{2}{*}{ Shading pattern } & \multicolumn{4}{|c|}{ Irradiance in each module $\left(\mathrm{W} / \mathrm{m}^{2}\right)$} & \multirow[t]{2}{*}{ GMPP (W) } & \multirow[t]{2}{*}{ LMPPs (W) } \\
\hline & M1 & M2 & M3 & M4 & & \\
\hline SP1 & 600 & 600 & 600 & 600 & 35 & - \\
\hline SP2 & 600 & 600 & 300 & 300 & 18.5 & 15.75 \\
\hline SP3 & 900 & 400 & 800 & 800 & 35.4 & 26.75 \\
\hline SP4 & 400 & 400 & 100 & 100 & 10.22 & 5 \\
\hline SP5 & 340 & 790 & 880 & 245 & 22.1 & $9.5-16-16.5$ \\
\hline SP6 & 560 & 560 & 320 & 995 & 25.2 & $11-21$ \\
\hline SP7 & 990 & 1015 & 890 & 890 & 55.3 & 27 \\
\hline SP8 & 110 & 990 & 876 & 453 & 24.7 & $7.1-10.7-22$ \\
\hline SP9 & 555 & 555 & 777 & 777 & 34.8 & 21 \\
\hline
\end{tabular}

Table 5: Results of the hybrid method PSO+P\&O

\begin{tabular}{lllllll}
\hline \multicolumn{7}{l}{ Scenario } \\
\hline Test & STC & PSC-1 & PSC-2 & PSC-3 & PSC-4 & PSC-5 \\
\hline 1 & 76.86 & 84.63 & 93.79 & 96.54 & 95.92 & 96.25 \\
2 & 97.69 & 94.43 & 97.11 & 95.78 & 94.61 & 96.25 \\
3 & 98.60 & 94.98 & 98.56 & 98.61 & 87.35 & 86.14 \\
4 & 74.93 & 80.68 & 94.50 & 85.57 & 91.61 & 94.08 \\
5 & 98.99 & 97.49 & 98.10 & 98.42 & 86.45 & 93.21 \\
6 & 98.75 & 99.68 & 98.29 & 85.38 & 88.27 & 88.77 \\
7 & 98.30 & 98.81 & 98.32 & 97.74 & 87.34 & 90.43 \\
8 & 95.66 & 98.01 & 84.07 & 98.04 & 84.01 & 91.78 \\
9 & 79.44 & 86.99 & 92.42 & 88.07 & 85.50 & 95.57 \\
10 & 96.45 & 98.03 & 98.14 & 93.30 & 97.95 & 97.04 \\
Mean & 91.57 & 93.37 & 95.33 & & 89.90 & 92.95 \\
\hline
\end{tabular}


Table 6: Efficiency $(\eta)$ and energy difference $\delta_{p}$.

\begin{tabular}{llll}
\hline Scenario & Tracking Method & $\eta(\%)$ & $\delta_{\mathrm{p}}(\%)$ \\
\hline STC & P\&O & 97.44 & - \\
& ANN+P\&O & 99.57 & +2.19 \\
PSC-1 & PSO+P\&O & 91.57 & -6.02 \\
& P\&O & 98.64 & - \\
& ANN+P\&O & 99.50 & +0.87 \\
PSC-2 & PSO+P\&O & 93.37 & -5.34 \\
& P\&O & 82.94 & - \\
& ANN+P\&O & 99.46 & +19.92 \\
PSC-3 & PSO+P\&O & 95.33 & +14.94 \\
& P\&O & 87.36 & - \\
& ANN+P\&O & 98.74 & +13.03 \\
PSC-4 & PSO+P\&O & 93.25 & +6.74 \\
& P\&O & 89.52 & - \\
PSC-5 & ANN+P\&O & 98.60 & +10.14 \\
& PSO+P\&O & 89.90 & +0.42 \\
& P\&O & 82.88 & - \\
& ANN+P\&O & 98.35 & +18.67 \\
\hline
\end{tabular}

Considering the Figs. 4, 5 and 6, and the values of efficiency in Table 6 , the hybrid methods $\mathrm{ANN}+\mathrm{P} \& \mathrm{O}$ and $\mathrm{PSO}+\mathrm{P} \& \mathrm{O}$ over performed the $\mathrm{P} \& \mathrm{O}$ algorithm reaching higher power values, and $\mathrm{ANN}+\mathrm{P} \& \mathrm{O}$ reaches the GMPP more efficiently, with more than $98 \%$ in all scenarios. Moreover, the energy gain was over 19\% in PSC-2 and over $18 \%$ in PSC-5. Although PSO+P\&O reaches the LMPP in some cases, it extracts power from the PV system more efficiently if compared to the P\&O algorithm for more complex scenarios such as PSC-5.

The choice of the better MPPT algorithm is intrinsically related to characteristics of the PV system. As discussed by Jiang et al. (2013b), the hybrid method ANN+P\&O can only be used if an experimental data for the training process of ANN can be provided. On the other hand, $\mathrm{PSO}+\mathrm{P} \& \mathrm{O}$ only shows improvements in comparison with conventional MPPT (P\&O) algorithm under PSC, or in cases of large PV systems.

\section{Conclusion}

In the present work, the $\mathrm{P} \& \mathrm{O}$ algorithm and two hybrid MPPT methods are reviewed and compared, namely $\mathrm{ANN}+\mathrm{P} \& \mathrm{O}$ and $\mathrm{PSO}+\mathrm{P} \& \mathrm{O}$. The results of all scenarios tested show that soft computing methods successfully contribute for the conventional algorithm to achieve the GMPP when the PV system are under PSC, resulting in a higher power extraction. $\mathrm{ANN}+\mathrm{P} \& \mathrm{O}$ and $\mathrm{PSO}+\mathrm{P} \& \mathrm{O}$ respectively achieved $98.93 \%$ and $92.96 \%$ on average in the PSC scenarios tested, whereas P\&O achieved $88.27 \%$ on average in such scenarios. Despite the effectiveness of hybrid method $\mathrm{ANN}+\mathrm{P} \& \mathrm{O}$, the algorithm requires substantial computing effort and it is relatively complex, principally for the training process.
The hybrid method with PSO successfully increased P\&O efficiency, under PSC, with low computational cost.

\section{Acknowledgment}

This research was financed in part by the Coordenação de Aperfeiçoamento de Pessoal de Nível Superior - Brasil (CAPES) - Finance Code 001.

\section{Author's Contributions}

Max Tatsuhiko Mitsuya: Participated in all experiments, coordinated the data-analysis and contributed to the writing of the manuscript.

Anderson Alvarenga de Moura Meneses: Designed the research plan, organized the study and contributed to the writing of the manuscript.

\section{Ethics}

This article is original and contains unpublished material. The authors have read and approved this manuscript and no ethical issues are involved.

\section{References}

Abdulkadir, M. and A.H.M. Yatim, 2014. Hybrid maximum power point tracking technique based on PSO and incremental conductance. Proceedings of the Conference on Energy Conversion, Oct. 3-14, IEEE Xplore Press, pp: 271-276.

DOI: 10.1109/CENCON.2014.6967514

Ahmed, J. and Z. Salam, 2014. A Maximum Power Point Tracking (MPPT) for PV system using Cuckoo Search with partial shading capability. Applied Energy, 119: 118-130.

DOI: $10.1016 /$ j.apenergy.2013.12.062 
Ahmed, J. and Z. Salam, 2015. An improved Perturb and Observe $(\mathrm{P} \& \mathrm{O})$ Maximum Power Point Tracking (MPPT) algorithm for higher efficiency. Applied Energy, 150: 97-108.

DOI: 10.1016/j.apenergy.2015.04.006

Ajiatmo, D. and I. Robandi, 2017. A hybrid Fuzzy Logic Controller-Firefly Algorithm (FLC-FA) based for MPPT Photovoltaic (PV) system in solar car. Proceedings of the International Conference on Power and Renewable Energy, Oct. 21-23, IEEE Xplore Press, Shanghai, China, pp: 606-610.

DOI: 10.1109/ICPRE.2016.7871149

Bataineh, K. and N. Eid, 2018. A hybrid maximum power point tracking method for photovoltaic systems for dynamic weather conditions. Resources, 7: 1-68. DOI: 10.3390/resources7040068

Batarseh, M. and M.E. Zater, 2018. Hybrid maximum power point tracking techniques: A comparative survey, suggested classification and uninvestigated combinations. Solar Energy, 169: 535-555. DOI: 10.1016/j.solener.2018.04.045

Beale, M.H., M.T. Hagan and H.B. Demuth, 2017. Neural network toolbox ${ }^{\mathrm{tm}}$ user' $\mathrm{s}$ guide how to contact mathworks.

Chaieb, H. and A. Sakly, 2018. A novel MPPT method for photovoltaic application under partial shaded conditions. Solar Energy, 159: 291-299.

DOI: 10.1016/j.solener.2017.11.001

Devi, V.K., K. Premkumar, A.B. Beevi and S. Ramaiyer, 2017. A modified perturb and observe MPPT technique to tackle steady state and rapidly varying atmospheric conditions. Solar Energy, 157: 419-426. DOI: 10.1016/j.solener.2017.08.059

El-Helw, H.M., A. Magdy and M.I. Marei, 2017. A hybrid maximum power point tracking technique for partially shaded photovoltaic arrays. IEEE Access, 5: 11900-11908.

DOI: 10.1109/ACCESS.2017.2717540

Femia, N., G. Petrone, G. Spagnuolo and M. Vitelli, 2005. Optimization of perturb and observe maximum power point tracking method. IEEE Trans. Power Electron., 20: 963-973.

DOI: 10.1109/TPEL.2005.850975

Gómez, M.F. and S. Silveira, 2015. The last mile in the Brazilian Amazon-A potential pathway for universal electricity access. Energy Policy, 82: 23-37. DOI: 10.1016/j.enpol.2015.02.018

Haykin, S., 1999. Neural Networks: A Comprehensive Foundation. 2nd Edn., Prentice Hall, Upper Saddle River, NJ, ISBN-10: 0139083855, pp: 842.

Ishaque, K. and Z. Salam, 2013. A deterministic particle swarm optimization maximum power point tracker for photovoltaic system under partial shading condition. IEEE Trans. Indus. Electron., 60: 3195-3206. DOI: 10.1109/TIE.2012.2200223
Ishaque, K., Z. Salam, A. Shamsudin and M. Amjad, 2012b. A direct control based maximum power point tracking method for photovoltaic system under partial shading conditions using particle swarm optimization algorithm. Applied Energy, 99: 414422. DOI: 10.1016/j.apenergy.2012.05.026

Jiang, L.L., D.L. Maskell and J.C. Patra, 2013a. A novel ant colony optimization-based maximum power point tracking for photovoltaic systems under partially shaded conditions. Energy Build., 58: 227-236. DOI: 10.1016/j.enbuild.2012.12.001

Jiang, L.L., D.R. Nayanasiri, D.L. Maskell and D.M. Vilathgamuwa, 2015. A hybrid maximum power point tracking for partially shaded photovoltaic systems in the tropics. Renewable Energy, 76: 53-65. DOI: 10.1016/j.renene.2014.11.005

Jiang, L.L., D.R. Nayanasiri, D.L. Maskell and D.M. Vilathgamuwa, 2013b. A simple and efficient hybrid maximum power point tracking method for PV systems under partially shaded condition. Proceedings of the 39th Annual Conference of the IEEE Industrial Electronics Society, Nov. 10-13, IEEE Xplore Press, Vienna, Austria, pp: 1513-1518. DOI: $10.1109 /$ IECON.2013.6699357

Karami, N., N. Moubayed and R. Outbib, 2017. General review and classification of different MPPT techniques. Renewable Sustain. Energy Rev., 68: 1-18. DOI: 10.1016/j.rser.2016.09.132

Kennedy, J. and R. Eberhart, 1995. Particle swarm optimization.

Lian, K.L., J.H. Jhang and I.S. Tian, 2014. A maximum power point tracking method based on perturb-andobserve combined with particle swarm optimization. IEEE J. Photovoltaics, 4: 626-633.

DOI: 10.1109/JPHOTOV.2013.2297513

Loukriz, A., M. Haddadi and S. Messalti, 2016. Simulation and experimental design of a new advanced variable step size Incremental Conductance MPPT algorithm for PV systems. ISA Trans., 62: 30-38. DOI: 10.1016/j.isatra.2015.08.006

Lyden, S. and M.E. Haque, 2015. A hybrid simulated annealing and perturb and observe method for maximum power point tracking in PV systems under partial shading conditions. Proceedings of the Australasian Universities Power Engineering Conference, Sep. 27-30, IEEE Xplore Press, Wollongong, NSW, Australia.

DOI: 10.1109/AUPEC.2015.7324803

Manickam, C., G.R. Raman, G.P. Raman, S.I. Ganesan and C. Nagamani, 2016. A hybrid algorithm for tracking of GMPP based on P\&O and PSO with reduced power oscillation in string inverters. IEEE Trans. Indus. Electron., 63: 6097-6106. DOI: $10.1109 /$ TIE.2016.2590382 
Messalti, S., A. Harrag and A. Loukriz, 2017. A new variable step size neural networks MPPT controller: Review, simulation and hardware implementation. Renewable Sustain. Energy Rev., 68: 221-233. DOI: 10.1016/j.rser.2016.09.131

Mitsuya, M.T. and A.A.M. Meneses, 2016. Utilização de redes neurais feed forward e layer-recurrent na busca do ponto de máxima potência em sistemas fotovoltaicos (in Portuguese). Proceedings of the 19th Brazilian Meeting on Computer Modeling, pp: 238-247.

Miyatake, M., M. Veerachary, F. Toriumi, N. Fujii and H. Ko, 2011. Maximum power point tracking of multiple photovoltaic arrays: A PSO approach. IEEE Trans. Aerospace Electron. Syst., 47: 367-380. DOI: 10.1109/TAES.2011.5705681

Nabipour, M., M. Razaz, S.G. Seifossadat and S.S. Mortazavi, 2017. A new MPPT scheme based on a novel fuzzy approach. Renewable Sustain. Energy Rev., 74: 1147-1169. DOI: 10.1016/j.rser.2017.02.054

Ons, Z., J. Aymen, A. Craciunescu and M. Popescu, 2016. Comparison of hill-climbing and artificial neural network maximum power point tracking techniques for photovoltaic modules. Proceedings of the 2nd International Conference on Mathematics and Computers in Sciences and in Industry, Aug. 17-17, IEEE Xplore Press, Sliema, Malta, pp: 19-23. DOI: 10.1109/MCSI.2015.24

Punitha, K., D. Devaraj and S. Sakthivel, 2013. Artificial neural network based modified incremental conductance algorithm for maximum power point tracking in photovoltaic system under partial shading conditions. Energy, 62: 330-340. DOI: $10.1016 /$ j.energy.2013.08.022

Radjai, T., J.P. Gaubert and L. Rahmani, 2014. The new FLC-variable incremental conductance MPPT with direct control method using Cuk converter. Proceedings of the 23rd International Symposium on Industrial Electronics, Jun. 1-4, IEEE Xplore Press, Istanbul, Turkey, pp: 2508-2513.

DOI: $10.1109 /$ ISIE.2014.6865014
Rezk, H., A. Fathy and A.Y. Abdelaziz, 2017. A comparison of different global MPPT techniques based on meta-heuristic algorithms for photovoltaic system subjected to partial shading conditions. Renewable Sustain. Energy Rev., 74: 377-386. DOI: 10.1016/j.rser.2017.02.051

Shaiek, Y., M. Ben Smida, A. Sakly and M.F. Mimouni, 2013. Comparison between conventional methods and GA approach for maximum power point tracking of shaded solar PV generators. Solar Energy, 90: 107-122.

DOI: 10.1016/j.solener.2013.01.005

Sundareswaran, K., S.P. Simon and P.S.R. Nayak, 2016. Gravitational search algorithm combined with $\mathrm{P} \& \mathrm{O}$ method for MPPT in PV systems. Proceedings of the Annual India Conference, Dec. 16-18, IEEE Xplore Press, Bangalore, India.

DOI: 10.1109/INDICON.2016.7838956

Sundareswaran, K., V.V. Kumar and S. Palani, 2015. Application of a combined particle swarm optimization and perturb and observe method for MPPT in PV systems under partial shading conditions. Renewable Energy, 75: 308-317.

DOI: 10.1016/j.renene.2014.09.044

Villalva, M.G., J.R. Gazoli and E.R. Filho, 2009. Comprehensive approach to modeling and simulation of photovoltaic arrays. IEEE Trans. Power Electron., 24: 1198-1208.

DOI: 10.1109/TPEL.2009.2013862

Xiao, W., W.G. Dunford, P. Palmer and A. Capel, 2007. Regulation of photovoltaic voltage. IEEE Trans. Indus. Electron., 54: 1365-1374. DOI: 10.1109/TIE.2007.893059 